\title{
ENTRE EL CAPITAL CULTURAL Y EL CAPITAL MONETARIO: LA ECONOMÍA EN LA MÚSICA CLÁSICA
} CONTEMPORÁNEA

\section{BETWEEN CULTURAL AND MONETARY CAPITAL: ECONOMICS IN CONTEMPORARY CLASSICAL MUSIC}

Xavier Mas i Sempere ${ }^{1}$

1. Máster en Sociología de las Políticas Públicas, Máster en Educación Secundaria, Licenciado en Comunicación Audiovisual, Licenciado en Historia y Ciencias de la Música y Título Profesional de Música. Personal Investigador en Formación, Departament de Sociologia i Antropologia Social, Universitat de València, España, Investigador invitado en el Departament de Sociologia I de la Universitat d'Alacant, (Programa VALi+d per a investigadors en formació, Referencia ACIF/2014/188, Generalitat Valenciana) (España). E-mail: xavier.mas@uv.es

Citación sugerida:

Mas i Sempere, X. (2017). Entre el capital monetario: la economía en la música clásica contemporánea. 3C Empresa, investigación y pensamiento crítico, 6(2), 59-76. DOI: <http://dx.doi.org/10.17993/3cemp.2017.060230.59-76/>. 


\section{RESUMEN}

A pesar de su carácter abstracto y etéreo, la música es uno de los elementos más importantes de nuestra sociedad. Constituida como hecho social $-\mathrm{y}$ con una notable repercusión- articula su desarrollo en relación al resto de elementos y actores de la sociedad. En nuestro trabajo mostramos, a partir de entrevistas y un grupo de discusión, cuáles son los discursos que, sobre música y economía, realizan los participantes en el campo de la música clásica contemporánea: compositores, directores, intérpretes, gestores culturales y públicos. De esta forma, podemos apreciar, en cada caso, qué valor se otorga y de qué forma se posiciona cada colectivo frente a los diferentes tipos de capital.

\section{ABSTRACT}

Despite its abstract and ethereal character, music is one of the most important elements of our society. Constituted as a social fact - and with a remarkable repercussion - it articulates its development in relation to the other elements and actors of society. In our work we show, from interviews and a discussion group, what are the discourses on music and economy by the participants in the field of contemporary classical music: composers, directors, interpreters, cultural and public managers. In this way, we can see, in each case, what value is given and how each group is positioned versus the different types of capital.

\section{PALABRAS CLAVE}

Música clásica contemporánea, capital cultural, economía, consumo, campo.

\section{KEYWORDS}

Contemporary classical music, cultural capital, economics, consumption, field. 


\section{INTRODUCCIÓN}

La música es la más abstracta de las artes. Hasta la invención de los medios de grabación sonora, prácticamente en la frontera del siglo XX, no fue posible fijarla en un soporte físico $y$, aun así, se necesita del tiempo para poder aprehenderla. Estas circunstancias esenciales han ayudado a construir un halo de misticismo a su alrededor. En ocasiones, alabando sus cualidades divinas -“La música... no tiene más que dos ingredientes a los que se pueda llamar dones de Dios: la capacidad de un cuerpo para vibrar y para producir sonido, y el mecanismo del oído humano que lo registra..." (Partch citado en Small, 1989: 18)- y, en otras, cuestionando pragmáticamente su valor para la humanidad -"Music is an innocent luxury, unnecesary [sic] indeed, to our existence, but a great improvement and gratification of the sense of hearing" (Burney citado en Simmel, 2003: 36).

Esta posición ideológica imposibilitó durante mucho tiempo un acercamiento científico social- al fenómeno musical. De hecho, durante muchas décadas fue la Etnomusicología, constituida originariamente como Musicología comparada, la encargada de abordar estas problemáticas con una metodología etnográfica. A lo largo del siglo XX, y gracias a las diferentes aportaciones desde la Sociología (Weber, 2002; Simmel, 2003) y la Musicología (Blacking, 2010; Nettl, 2001; Merriam, 2001), hemos conseguido abordar metódicamente la música y poner los cimientos para el desarrollo de la Sociología de la música.

Llegados a este punto ya podemos plantearnos la música como un objeto social más. Un elemento, a la vez, producto y espejo de la sociedad y una parcela más en la que podremos identificar el juego de las relaciones sociales. Siguiendo a Jacques Attali:

\footnotetext{
"hay que aprender a juzgar una sociedad por sus ruidos, por su arte y por sus fiestas más que por sus estadísticas. Al escuchar los ruidos, podremos comprender mejor adónde nos arrastra la locura de los hombres y de las cuentas, y qué esperanzas son todavía posibles" (1977:11).
}

En el presente trabajo, presentaremos los resultados de un análisis sociomusicológico que se ubica en la intersección entre música y economía. Gracias a los discursos de los diferentes actores sociales, conoceremos cómo se articula esta relación y de qué forma, artistas, públicos y gestores, conviven en un contexto específico -el de la música clásica contemporánea- que conjuga, constantemente, capital económico y capital cultural.

\section{DESARROLLO}

\subsection{OBJETIVOS}

La investigación que desarrollamos en las páginas siguientes pretende conocer cuáles son los discursos que se realizan, en el contexto cultural de la música clásica contemporánea, sobre el binomio música y economía. Ante la articulación de diferentes tipos de capital cultural, humano, monetario-podremos identificar qué valores se otorgan y qué posiciones discursivas se adoptan desde cada uno de los colectivos analizados. Todo ello, nos permitirá 
saber cuál es la incidencia de la economía en este ámbito cultural y qué problemáticas se identifican desde cada grupo.

\subsection{DELIMITACIÓN Y METODOLOGÍA}

Este trabajo se encuadra dentro del proyecto de tesis doctoral La música clásica contemporánea: una perspectiva sociomusicológica. Una investigación más amplia que aborda, también, las programaciones sinfónicas de las orquestas y auditorios, la difusión musical en los mass media, la producción discográfica y el consumo cultural en streaming y en conciertos. Para la elaboración de este artículo, hemos incluido parte del material obtenido para el epígrafe "colectivos artísticos".

Los grupos sociales analizados han sido: compositores, intérpretes -entre los que incluimos instrumentistas y directores-, directivos de conservatorios superiores, gestores públicos gerencias y direcciones artísticas de centros culturales- y el público -concretado en abonados a ciclo sinfónico-. Dada las limitaciones económicas y temporales del estudio, hemos reducido la muestra de intérpretes y compositores a sujetos que, durante las temporadas 2014-2015 i 2015-2016 han estrenado o interpretado obras en auditorios del País Valenciano. En el caso de gestores y directivos de conservatorios, hemos extendido la muestra al conjunto del estado. A pesar de la limitación territorial, y tal y como muestra la figura 1, la muestra obtenido nos permite obtener casos de 10 provincias -que se traduce en 7 comunidades autónomas-. Efectivamente, esta muestra no puede ser representativa del conjunto estatal -como mucho, de la programación cultural valenciana-. En cualquier caso, nos sirve como muestra exploratoria para comprobar la validez de la metodología abordada. Por una cuestión ética, relacionada con el mantenimiento del anonimato de los participantes, no podemos especificar el origen de los gestores públicos ni de los directivos de conservatorio. Teniendo en cuenta el escaso número de centros superiores y auditorios con programación sinfónica, el hecho de indicar la provincia de origen permitiría identificar, fácilmente, al sujeto participante en la investigación. Sí que podemos indicar que las entrevistas se realizaron en 4 comunidades autónomas diferentes. Finalmente, los discursos del público se obtuvieron a partir de un grupo de discusión, con abonados sinfónicos del Auditorio de la Diputación de Alicante, celebrado a principios de 2017. 


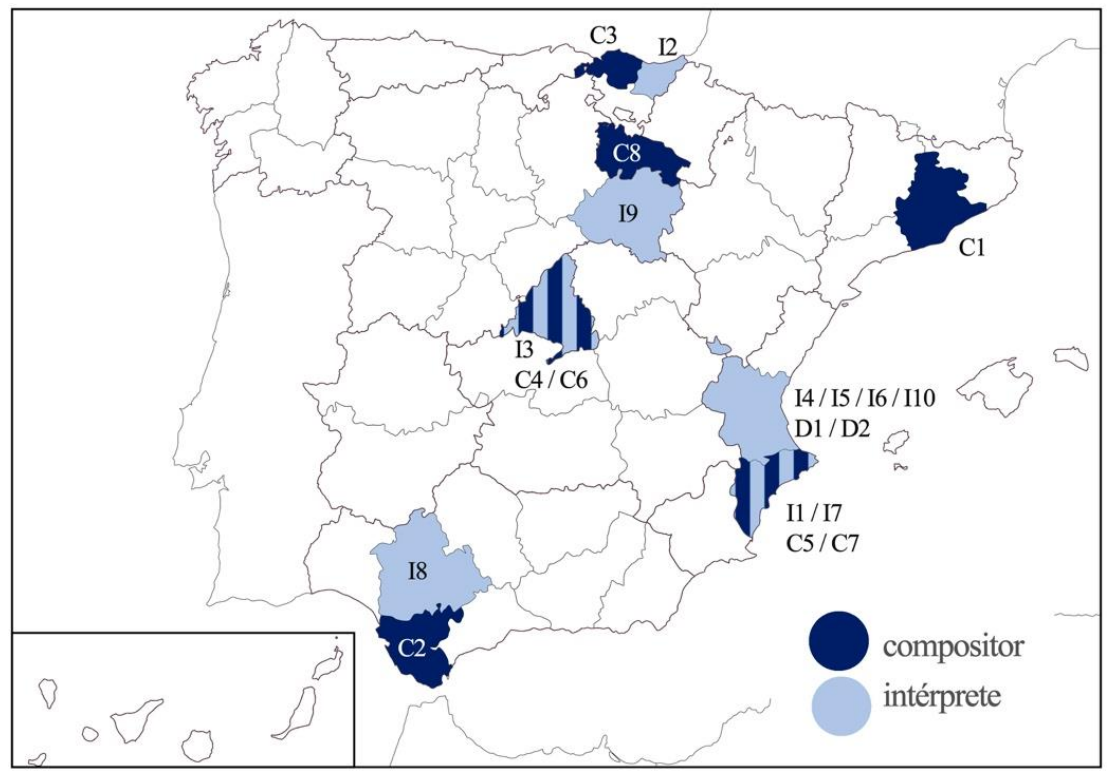

Figura 1. Mapa con el origen geográfico de los compositores e intérpretes entrevistados. Fuente: elaboración propia.

Para este trabajo, como ya se ha indicado, se han utilizado exclusivamente técnicas cualitativas: entrevista semi-estructurada y grupo de discusión. En el proyecto original, se articula, también, un notable corpus cuantitativo, pero, en esta ocasión, este planteamiento metodológico nos permite obtener los discursos sobre los que se realizará el pertinente análisis.

Resulta imprescindible, en esta ocasión, señalar que tanto en las entrevistas como en el grupo no se plantea ninguna pregunta ni se alude directamente a la economía. Todas las muestras que, en este caso, aportaremos, surgen espontáneamente y son siempre, los propios sujetos, los que dirigen la atención de su discurso hacia elementos de cariz económico.

\subsection{MARCO TEÓRICO}

Las aportaciones de Bourdieu a la sociología son centrales en este trabajo. Su análisis del capital cultural (1987) nos permite identificar tres estados diferentes: incorporado, objetivado e institucionalizado. Igualmente, y no menos importantes, son la noción de campo (1990) y la de distinción (1991).

De las cuatro ramas de la sociomusicología contemporánea identificadas por Philip Tagg, asumimos, en esta ocasión, las dos que se vinculan con el significado social de la música (Tagg, 1982) y con el proceso comercial e industrial (Philo \& Miller, 2010). Las aportaciones de Jacques Attali, finalmente, son fundamentales en nuestro propio ejercicio de relectura de la música como objeto de consumo:

“Hoy día también, dondequiera que la música está presente, también está ahí el dinero. Incluso si nos limitamos a las cifras, vemos que en ciertos países ya se le consagra más dinero que a lavarse, leer o beber. La música, disfrute inmaterial convertido en mercancía, viene a anunciar una sociedad del signo, de lo inmaterial vendido, de la relación social unificada en el dinero" (1977: 10-11). 
Este concepto de lo "inmaterial vendido" nos sitúa en la órbita del capitalismo informacional: esta penúltima evolución del capitalismo que hizo posible la burbuja de las puntocom y que juega, hoy en día, la guerra de los contenidos en las plataformas multimedia. El mundo post-material y el mundo digital se dan la mano ante la atenta mirada de la música clásica contemporánea. Una manifestación cultural ya longeva pero que lucha, todavía hoy, por ubicarse en espacios, prestigios y lógicas.

\section{RESULTADOS}

A continuación, exponemos los resultados de la investigación, estructurados en tres apartados. Primero, desarrollaremos las aportaciones de los abonados en el grupo de discusión. Segundo, abordaremos de forma conjunta las entrevistas a compositores e intérpretes [instrumentistas] y directores. Finalmente, las ideas recogidas en las entrevistas a gestores culturales y directivos de conservatorios. En la tabla 1, presentamos los datos sociodemográficos básicos de las personas participantes.

Tabla 1. Participantes en la investigación.

\begin{tabular}{|c|c|c|c|c|c|c|c|c|}
\hline \multicolumn{3}{|c|}{ Abonados } & \multicolumn{3}{|c|}{ Compositores } & \multicolumn{3}{|c|}{ Intérpretes } \\
\hline A1 & Mujer & 1959 & $\mathrm{C} 1$ & Hombre & 1962 & 11 & Hombre & 1970 \\
\hline$A 2$ & Hombre & 1964 & C2 & Hombre & 1957 & 12 & Hombre & 1967 \\
\hline A3 & Hombre & 1964 & C3 & Hombre & 1963 & 13 & Mujer & 1960 \\
\hline A4 & Hombre & 1944 & C4 & Hombre & 1954 & 14 & Hombre & 1973 \\
\hline A5 & Hombre & 1952 & C5 & Hombre & 1962 & 15 & Hombre & 1978 \\
\hline \multirow[t]{5}{*}{ A6 } & Mujer & 1967 & C6 & Hombre & 1958 & 16 & Hombre & 1979 \\
\hline & & & $\mathrm{C7}$ & Hombre & 1952 & 17 & Hombre & 1978 \\
\hline & & & $\mathrm{C} 8$ & Hombre & 1955 & 18 & Hombre & 1982 \\
\hline & & & & & & 19 & Mujer & 1986 \\
\hline & & & & & & 110 & Mujer & 1978 \\
\hline \multicolumn{3}{|c|}{ Directores } & \multicolumn{3}{|c|}{$\begin{array}{l}\text { Directivos } \\
\text { conservatorio }\end{array}$} & \multicolumn{3}{|c|}{ Gestores culturales } \\
\hline D1 & Hombre & 1978 & F1 & Hombre & 1957 & $\mathrm{G} 1$ & Hombre & 1955 \\
\hline \multirow[t]{3}{*}{ D2 } & Hombre & 1957 & F2 & Hombre & 1956 & $\mathrm{G} 2$ & Hombre & 1966 \\
\hline & & & F3 & Hombre & 1962 & G3 & Mujer & 1961 \\
\hline & & & F4 & Hombre & 1959 & G4 & Hombre & 1970 \\
\hline
\end{tabular}

El trabajo con el grupo de discusión nos permitió identificar, como elemento central, la existencia de una noción de comunidad entre los abonados. A pesar de que no tengan un vínculo personal demasiado estrecho, el mero hecho de compartir una trayectoria de consumo cultural común y de saberse apelados por unas citas periódicas, construye un 
sentimiento de pertenencia a un colectivo: abonados del ADDA (Auditorio de la Diputación de Alicante).

En nuestro análisis pudimos comprobar la articulación de una distinción, interna al grupo, según los conocimientos musicales. Así, el mayor prestigio se alcanzaba con el capital cultural -musical- institucionalizado. En su ausencia, se podía aludir, como mínimo, al capital cultural incorporado -vinculado, bien a la longevidad de la experiencia de abonado, bien al consumo de crónicas y material musical divulgativo-. Esta situación de desigualdad -que nos permitió vislumbrar un conflicto social basado en una lucha de legitimaciones [“¿Y vosotros creéis que todas las personas que vienen al auditorio tienen tantos conocimientos como estoy viendo que tenéis vosotros?" (A6)]- se neutralizó por medio de tres elementos que constituían el punto de encuentro y el mecanismo de sutura del grupo. Estos son: precio, proximidad y gusto. El primer elemento es de factura, evidentemente, económica. El segundo, parcialmente, también se relaciona con el coste del desplazamiento. El tercero sería la noción más claramente estética. A pesar de ello, con una lectura bourdiana (1991) que plantea que el propio gusto es una construcción basada en la clase social-podríamos considerar, también, la determinación económica de este elemento y el requisito de contar con un cierto nivel socioeconómico para poder acceder a esta oferta.

El abono sinfónico del ADDA, se vendió, en la temporada 2016-2017, a unos precios que oscilan entre los $210 €$, para la zona C, y los $290 €$, para las zonas A y B. Estas cifras suponían abonar entre $17,5 €$ y $24,17 €$ en cada uno de los 12 conciertos ofertados. De haberse comprado sueltas, el total de las entradas de la temporada asciende a $400 €$ y $540 €$, respectivamente -lo que nos muestra un ahorro del $45,5 \%$ y del $46,3 \%$-. Cifras y porcentajes aparte, la idea del ahorro está muy extendida entre los abonados: "es un chollo" (A2); "me reafirmo en lo primero: sigue siendo un chollo" (A5). Se considera su posesión como un privilegio que, en caso de perder, es muy difícil volver a conseguir: "ser abonado también es... porque si te desprendes del abono te da la sensación de que no es muy fácil conseguir otro, ¿iverdad?" (A5).

La propia creación del auditorio, inaugurado en la temporada 2011-2012, ha supuesto la satisfacción de una demanda que llevaba largo tiempo esperándose y que se paliaba con desplazamientos a centros culturales cercanos: "Antes no existía nada. Tenías que ir a Murcia o a Valencia. Ibas a Murcia y veías autobuses de la Sociedad de Conciertos de Alicante -tres-. Decías: 'ostras, ¿qué pasa aquí?' y 'iqué auditorio tiene Murcia! ¿Y Alicante?'” (A3). Vista en perspectiva, además, la facilidad de transporte privado actual contrasta con las experiencias pretéritas de desplazamiento des de las entidades municipales menores: "los que vivíamos en la montaña, perdidos, que no había transporte: que era un autobús por la mañana, un autobús por la tarde y nada más pues eso era complicado" (A2). Estudios posteriores tendrían que analizar el área de impacto geográfico de estos equipamientos culturales. Con todo, y según nos comenta el personal de taquillas del auditorio, la mayoría de abonados son de la propia capital alicantina o de las cercanías. De esta forma, en efecto, se cumple el papel de centro de proximidad.

El elemento del gusto nos muestra una situación de conflicto que aúna referencias al capital cultural y al capital monetario. La barrera más explícita entre gusto y disgusto en la música 
clásica lo marca la música clásica contemporánea -aquellas producciones compuestas entre los inicios del siglo XX y especialmente aquellas que utilizan un lenguaje más cercano a las corrientes vanguardistas o experimentales-. Así pues, se considera el sinfonismo del Clasicismo, Romanticismo y Post-Romanticismo como la música propia de la programación del ciclo de abono y en la que coinciden los gustos de todos. De hecho, se considera que toda la programación gira alrededor de unas figuras históricas de referencia:

\footnotetext{
"tú miras el programa y hay varios [compositores] que se repiten, que es lo que digo yo. $Y$, ¿por qué se repiten? ¿Por qué gustan? [...] Está todo el mundo, precisamente, porque el programa es ese. Si fuera otro, seguramente, el teatro... la mitad de las butacas estarían vacías" (A5).
}

En el momento que se les plantea la opción de programar más música clásica contemporánea -incluso, de llegar a ofertar una temporada monográfica- la respuesta es muy contundente: "es que es muy raro. Eso... Y además es que no vendría nadie. Entonces, ¿qué? Esto es un negocio" (A6). Efectivamente, los propios abonados no pierden en ningún momento de vista la realidad económica del auditorio. Aunque centro público, supone un centro de negocios que tiene que atraer a los públicos y compensar, con las entradas y abonos, las costosas contrataciones de las agrupaciones e intérpretes solistas: "yo no sé el presupuesto lo que costará traer a la Filarmónica de... de Londres, pero seguro que cuesta un dineral [...] debe ser un pastón increíble lo que cuesta eso" (A5); "Tú cuenta hotel. Setenta euros por cabeza, más o menos Setenta euros por cabeza, cien. Cuanto son, ¿̇iete mil?" (A2).

Si nos centramos en el capital cultural podemos identificar un corte estilístico, producido a lo largo del período histórico antes mencionado, y que supone la gran fisura entre entendidos y legos. Partiendo de la base que el público con escaso capital cultural utiliza la melodía como fenómeno acústico básico para guiar su audición y descodificar el mensaje artístico -"el problema es la melodía. O sea, si tú vas siguiendo la melodía: la música te gusta" (A5)-, la utilización de nuevas fórmulas compositivas centradas en el ritmo o en la tímbrica (texturas) les deja completamente desarmados:

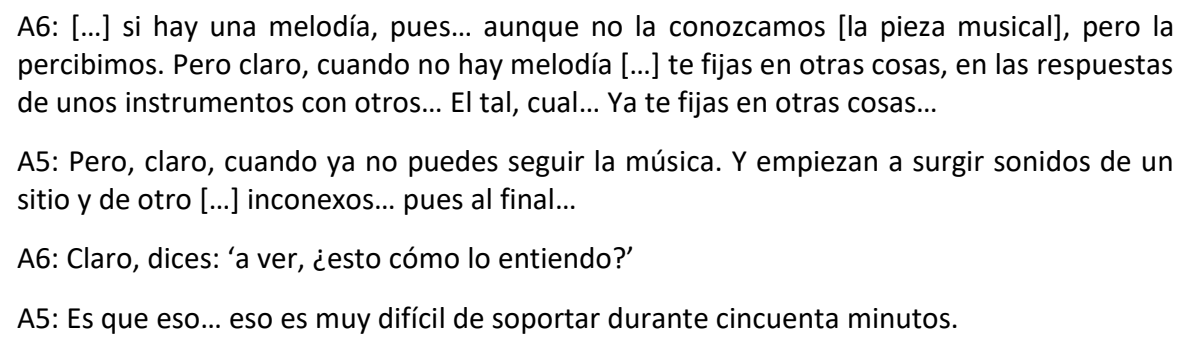

Esta situación socioartística, especialmente desarrollada en el campo música, deja a parte del grupo en una situación de total desamparo. Los mecanismos incorporados no sirven para descodificar y, con ello, poder llegar a apreciar, primero, y estimar, después, las nuevas formas musicales. La desigualdad inicial del grupo se recrudece en este punto en el que, incluso, se llega a establecer la lógica de las relaciones docente-discípulo:

A6: ¿Y cómo lo soportáis vosotros?

A2: Porque nos fijamos en otras cosas. 
Pasamos, a continuación, a los discursos de los compositores e intérpretes. Hay que señalar, antes que nada, que ninguno de los compositores entrevistados puede ganarse la vida, exclusivamente, por medio de la composición y han de dedicarse a otras ocupaciones -la docencia, principalmente-. Este hecho sí que se da en el caso de los intérpretes o los directores, aunque, de algún modo todos tienen cierta vinculación con el ámbito académico.

Las primeras cuestiones que abordábamos en las entrevistas se referían a los orígenes del interés personal por la música y a la formación. Algunos de los entrevistados referían haber recibido regalos, en su niñez, en forma de instrumentos musicales: "Me regalaron una guitarra y no hubo más opción" (I1); "el meu joguet preferit era un tambor" (I5). En otros casos, se alude a la experiencia musical de algún familiar cercano. Es aquí donde podemos ver, más claramente, el efecto Arrow generalizado que menciona Bourdieu (1987): "el acercamiento es muy natural: yo he visto un violonchelo en... en casa junto al... resto del mobiliario" (12). Observamos, en cualquier caso, que la cantidad de capital cultural institucionalizado acumulado por el familiar músico es irrelevante. Tanta influencia puede tener el padre que es catedrático del instrumento en el conservatorio, como el tío-abuelo que es miembro de una sociedad musical típica del País Valenciano: "Siempre recuerdo que... que quería dedicarme a esto. Siguiendo una tradición familiar, también" (C3).

Un elemento que denota el contexto socioeconómico de partida de los músicos es, precisamente, el relato que se elabora alrededor de la formación. Resulta bien significativo que apenas se realicen referencias al coste de los estudios: una formación que incluye la compra de instrumentos musicales, las clases magistrales particulares con artistas de referencia y el desplazamiento exterior para actuar en salas del circuito internacional. De hecho, en algunos verbátims, encontramos alguna alusión, pero dentro de una completa normalidad: "Ahora tienes más opciones de irte fuera, de conseguir unas becas, de... de... yo de hecho también me fui a Viena a hacer mis cursos o a... Londres a hacer... a las masterclasses, ¿̇no? Pero ahora está todo más al día..." (I10).

Lógicamente, cuando más hincapié se hace en estos aspectos es, precisamente, cuando más humilde es el origen del músico:

\footnotetext{
"Me considero un afortunao ya que... mis padres han podido pagarme un violín, han podido pagarme los estudios y han podido pagarme clases particulares ya que no es fácil, eh... quiero decir, o sea, tú naces en un lugar o naces en un sitio y, claro, lo público, eh... te permite [solamente estudiar] en ese mismo lugar" (I8).
}

Estos dos ejemplos extremos que hemos presentado, se ubican en el vértice de la posición discursiva económica. Como muestra la figura 2, las referencias a la formación musical se completan con alusiones al capital humano invertido -reconvertido aquí en esfuerzo personal- y al capital cultural. Esta es, sin duda, la posición más habitual y la más estrechamente vinculada a la música en su vertiente estética: "Tuve la suerte de... de dar con un profesor que me... enseñó muy bien desde el principio y me motivó muy bien desde el principio entonces fui bastante encaminado" (19); "No tuve una educación musical demasiado buena, entre otras cosas porque no se me permitió -como no se... como no se le permite, incluso, a día de hoy a ningún niño que empieza a estudiar- dedicarse en 
exclusiva a lo que ya es su vocación de manera evidente" (I1). "Mi formación musical creo que fue desastrosa. Yo estudié en el Conservatorio de Madrid y... y tuve que desaprender lo aprendido en gran medida, ¿no?" (C2). "Tú sales y tú... tienes una... una formación académica que no tiene nada que ver con lo que hay en la... en realidad, en la música. Entonces esa realidad tardas años en... en asumirla, en aceptarla y en...» (C5). "Content però crec que se podria millorar molt en la formació musical, avui en dia, en el nostre país» (16).

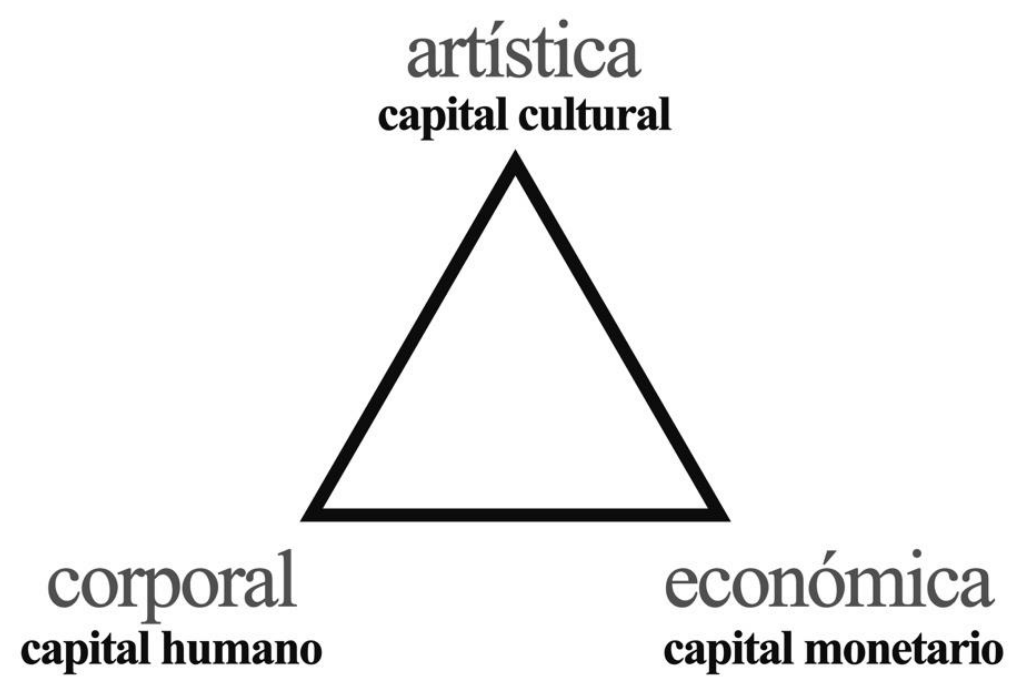

Figura 2. Elementos prioritarios en la formación musical.

Fuente: elaboración propia.

Una vez abierta esta cuestión, y como ya hemos visto, se empiezan a plantear cuestiones relativas a la calidad de la enseñanza o a la dialéctica entre plan de estudios y habilidades necesarias para el desempeño de una profesión. Hemos resumido, en la figura 3, las diferentes posiciones discursivas que se desarrollan en este ámbito y que conjugan el binomio mejor-peor con los límites temporales del presente y el pasado y los límites territoriales del interior y el exterior del estado. 


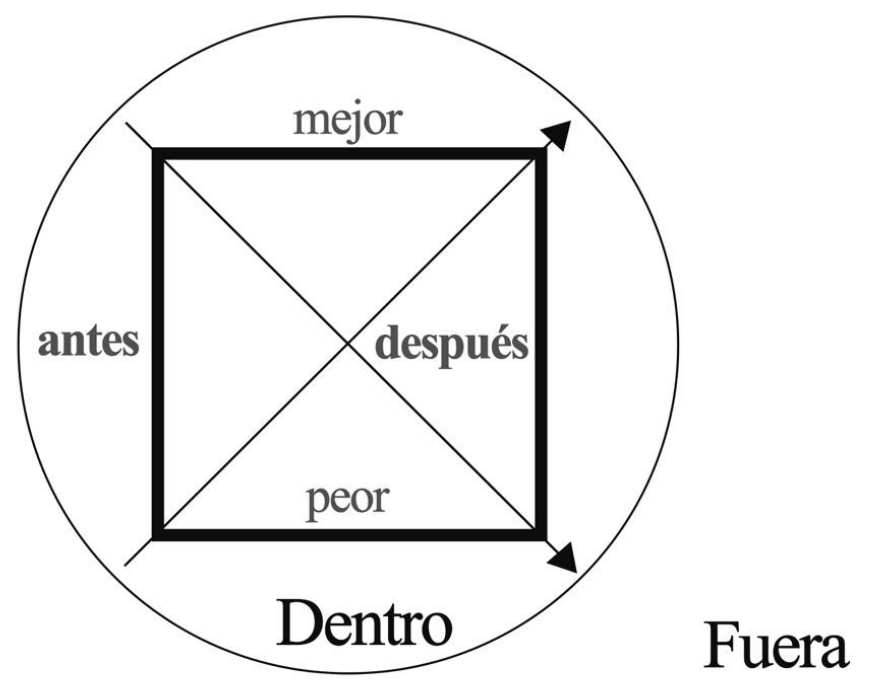

Figura 3. Noción de la evolución histórica de la formación. Fuente: elaboración propia.

El conflicto que introducíamos, anteriormente, entre el público y la creación actual tiene, también, un seguimiento dentro de estos colectivos. A primera vista, y como posible hipótesis de trabajo, hemos observado un cierto punto de inflexión entre los discursos de algunos miembros de la generación de 1950 y la generación de 1960. Para los primeros, las nuevas formas de composición suponen una revolución frente a un pasado clásico que, todavía, les llega por mano de sus profesores: "Sentía incluso, aunque lo estudiaba, un cierto desprecio por la... por las, digamos, las técnicas más eh... canónicas o académicas de lo que es la composición y el proceso de escritura musical: llámese contrapunto, llámese armonía funcional, etcétera» (C4), "Me convertí en un ser autodidacta que renegaba de todo el escolasticismo y de toda la escuela, digamos, tradicional. Que también fue un error" (C2). Para los segundos, este paradigma estético es una opción en su formación pero que no puede limitarles su sentido creativo: "Tot el gruix de repertori que tocava era romàntic, impressionista, etcètera. I a llavors, tot lo que era assignatures teòriques del conservatori, eh... i tota l'estètica diguem-ne de tots els que composaven i els professors de composició etcètera era un llenguatge que a mi no $\mathrm{m}$ 'interessava gens» (C1), "Lo que no escucho nada es vanguardias de los sesenta y setenta que me aburren. Es decir, tomé ya cursos con Luis de Pablo, ya me enteré que existía Pierre Boulez, que existía Varèse, que existía Xenakis, que existían todos estos y no me interesaban ninguno. No me interesaba jamás" (C5).

Este conflicto acaba asociado, finalmente, al poder practicado desde la posición privilegiada de la academia: "En Estados Unidos sí que están mirando hacia delante. Si mirar hacia delante significa que están abiertos, en la educación musical, a todo tipo de... de tendencias. Y no tienen ningún tipo de prejuicio contra nada. Aquí hay mucho prejuicio todavía. Entonces aquí... aquí hay un problema. Es que si nos ponemos en plan concreto aquí hay un problema en los conservatorios. Hablo de composición. Los departamentos de composición están todos tomados, han sido todos tomados, por un... por una misma escuela" (C5). 


\section{compositor}

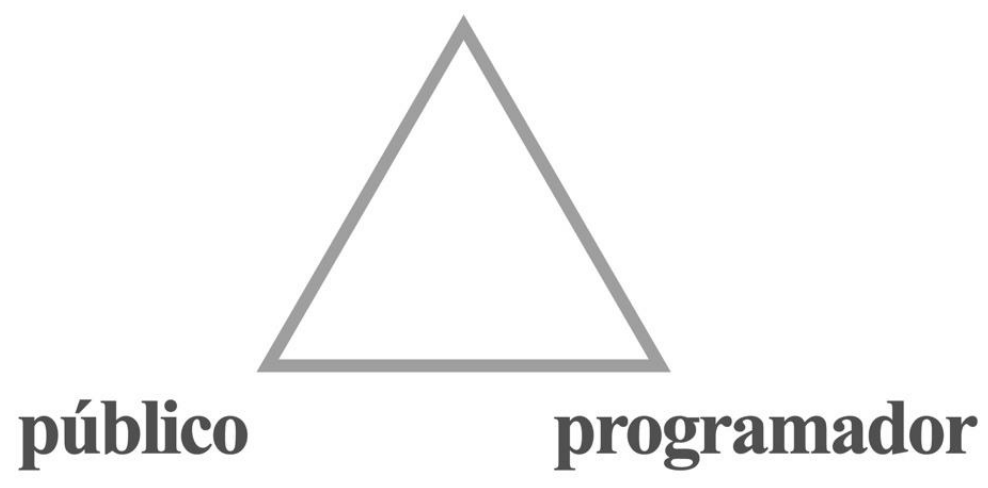

Figura 4. El conflicto de la desafección.

Fuente: elaboración propia.

"No existen obras en la historia de la humanidad pensadas para matar a los demás" (C2). Efectivamente, en esta situación de divorcio, todos los compositores entrevistados se sitúan discursivamente en la idea de agradar a los demás: "Hi havia una... una crítica que em va arribar d'un bloc que deia "el compositor -però aixís, eh?, era molt bona la frase- el compositor parece querer complacer al público". Jo vaig dir... vaig pensar... "Home: ino parece: quiero complacer!»" (C1)". Por tanto, nuestra mirada, aquí, tiene que dirigirse a la idea de responsabilidad que se tiene de esta situación actual. Entre las diferentes aportaciones hemos encontrado un triángulo de culpabilidad que mostramos en la figura 4.

Aquellos que se centran en la parte estética, responsabilizan al creador: "La música contemporánea entonces se asocia con: no conecta con el público. Entonces no sé si el problema es... siempre es del público. No estoy tampoco... no quiero culpar a una parte o a la otra, eh. Pero soy de los que piensan que la gran música, generalmente, tiende a llegar» (D1)". Desde la posición del músico -con un capital cultural específico- se echa de menos una mayor implicación del público: "Se li ha d'exigir una miqueta. Eh? No se li ha de donar sempre la raó, se li ha d'estar exigint" (C7). Y como posible solución, además, se insiste en la necesidad de fomentar la educación musical en todos los niveles educativos: "El público, la mayor parte del público, no tiene ni idea de todo esto porque les falta la educación musical" (18); "Yo creo que es una labor de educación: desde pequeño" (C3). Finalmente, la tercera posición -que comparten tanto compositores como intérpretes- lanza balones fuera hacia otro colectivo más vinculado a la tarea administrativa que al desarrollo artístico: "Yo en mi experiencia personal no he conocido demasiados buenos programadores. Aquí en España creo que adolecemos de... bastante de este sector. De buenos... buenos profesionales programando" (I1); "Los gestores no saben, primero, muchas veces qué es lo que están programando y no aman lo que programan. [...] Es más, muchas veces ni conocen lo que están programando" (C4). En este caso, la problemática no es tanto la ausencia del 
público como la falta de buenas estrategias para atraerlo: "El público existe lo que no existen son los buenos gestores". El mayor desprestigio para la figura del gestor público, aún más, es su consideración de cargo político. Un hecho que, actualmente, supone a priori un demérito: "la formación de un público es una tarea que depende mucho, por supuesto de intérpe... de intérpretes también, pero depende vitalmente de la gente que está detrás... en política y encargándose de... de las programaciones" (I1).

Finalmente, abordamos la participación en el estudio de los gestores públicos y directivos del conservatorio. Como ya indicábamos anteriormente, estos colectivos se han estudiado de manera específica y conjuntamente por su posición de poder en el sistema. Unos son los encargados de diseñar las programaciones y estrategias comunicativas de los centros culturales. Los otros, por su parte, son los encargados de plantear y desarrollar los proyectos educativos con los que se gestionan los conservatorios superiores: institución que supone en la práctica -no así en la legislación- el equivalente para la música de la facultad.

Este binomio de colectivos es el más implicado en el aspecto económico de la música. Por un lado, los docentes se ubican en el principio de la trayectoria profesional del artista y tienen, como referente, el camino exitoso de sus discípulos: "Hay un objetivo que está por encima de cualquier otro y es: hay una generación que es más joven, que está formándose ahora, preparándose para el futuro, para su futuro profesional y el objetivo número uno es sacarlos p'alante en las mejores condiciones posibles" (F1). El objetivo principal, pues, es tratar de "ayudarle. Tratar de abrirle las máximas puertas posibles" (F2).

Por otro lado, los gestores culturales son los que cierran la cadena. Ellos son los que ponen en contacto a públicos, intérpretes y compositores y los que, con el desarrollo de su trabajo, dotan de sentido a la formación artística. Aquí podemos encontrarnos posiciones más mercantilistas "Evidentemente, lo primero que miramos es la disponibilidad económica y a partir de ahí pues tenemos una serie de digamos de necesidades que atender específicamente en este centro que es un auditorio" (G1) o creativas

“En general, el procés... el procés de programar, programàtic, és un procés absolutament creatiu. És un procés que és exactament el mateix que programar un concert, inclús m'atreviria a dir, que és el mateix que construir els clímaxs d'una simfonia" (G4).

El objetivo final es siempre compartido: llenar los auditorios. La diferencia entre unos y otros, radica en el tipo de público al que se aspira: "Me da la sensación de que los auditorios y las salas de concierto se están quedando cada vez con un público más... de más edad. Entonces, a mí me gustaría que eso se renovara" (G3); "yo lo que quiero es tener el teatro lleno, si son jóvenes mejor, pero lo que yo quiero es tener el teatro lleno" (G2).

La relación con la música clásica contemporánea es difícil. Por un lado, existen las reticencias del público -“[los públicos] oyen música contemporánea y es como: «iuf!... iAy! qué ruidos. Yo no quiero eso ni verlo, ni escucharlo»" (G2)- y por otro las dificultades añadidas que supone su propia caracterización -“la historia que tiene, es que... empiezan a salir historias de instrumentos rarísimos que no tiene nadie, que hay que alquilarlos, es 
decir, que... programar repertorio contemporáneo es mucho más caro que el repertorio tradicional" (G2).

Todas estas circunstancias denotan el agotamiento del modelo actual. Un modelo basado en elementos sociales del siglo XIX y que suponen serias dificultades para conectar con el público y dar rodaje a las nuevas creaciones. El mismo formato del concierto -construido a partir de la sucesión de diferentes obras sinfónicas, con una duración que oscila, habitualmente, entre las dos y las tres horas, y con unas entradas que pueden alcanzar precios relativamente altos- ya supone una selección de público. Es una puesta en escena idónea para la música del momento histórico en que se desarrolló.

Aún más, la relación con la música clásica contemporánea puede basarse en dos elementos diferentes. Uno, la responsabilidad de difundir o de crear, respectivamente, un nuevo patrimonio: "yo no prescindiría Stockhausen en un conservatorio... ni para estudiarlo ni para interpretarlo [...] ¿Pero... qué quieres que te diga? Pues... pues... no me apetece" (F1); "los gestores culturales tenemos una obligación con la creación actual porque para que exista un patrimonio en el futuro tenemos que apoyar la creación hoy. Si no, no existiría este patrimonio en el futuro" (G2). Dos, el gusto por la propia música y la voluntad de compartir el placer de su consumo:

\footnotetext{
"Eixa és la manera en la que jo crec que tens que mirar al públic. Què es lo que jo he tingut la sort de conèixer en vint i pico o trenta anys de vida professional que estos encara no han vist? I jo com puc fer pa que ho comprenguen? Jo com puc fer pa que esta gent comprenga... Turangalila de Messiaen que ja és un clàssic i seguixen sense comprén-lo. Com puc fer perquè vegen la bellea del moviment del Jardin de l'amour. Com tinc que tocar això i com tinc que programar-ho i com tinc que vendre-ho per a que el vinga diga: «ah, sí! Ara entenc el paisatge que volies que vegera»" (G4).
}

Dentro de esta pluralidad de posiciones, en el momento en que se plantea la necesidad de la renovación, los discursos se homogeneizan. Observamos, pues, en este punto el paso de una difusión centrada en el qué, es decir, en el objeto artístico -el repertorio-, a una difusión centrada en el cómo, esto es, en la forma en la que se desarrollará y se publicitará el contenido musical: "si tu fabriques el producte i no te'l compren, tindràs que inventar algo. Anem a canviar el color de la caixa, no sé. A lo millor és una qüestió de reclam" (F4); "Si se lo haces llegar de otra manera, puedes enganchar a determinado público" (G2). Bajo este paradigma, incluso, un posible fracaso de la obra se tendría que replantear en términos de programación:

\footnotetext{
"[Los compositores] no són lliures a l'hora d'imposar -poden crear lo que vulguen- ni jo, ni ningú. Jo puc fer lo que vulga. I intentar que t'agrade o no. I tu em diràs: "tio, passe: lo que m'estàs contant". I jo pensaré: "per què no li ha agradat? Perquè és un bodrio?, -que pot serperquè no he sabut explicar-li-ho?, perquè ha estat mal interpretat?, perquè no era l'entorn programàtic adequat?, perquè no era l'hora adequada?, perquè no era... etcètera" (G4).
}

Esta posición, además, concilia la libertad creativa y las opciones de consumo del público:

"La llibertat creativa seguirà estant però lo que no podem exigir és a la societat, és que mos compre eixa llibertat creativa. Perquè la societat no compra llibertats: la societat compra -el consum- està en lo que m'interessa, en lo que m'agrada i en lo que em fa disfrutar" (F4). 
El debate, así, puede superar los ámbitos económico y estético para llegar una reflexión ética.

\section{CONCLUSIONES}

La música, como elemento social, es un instrumento -"de conocimiento que incita a descifrar una forma sonora del saber" (Attali, 1977: 11)- privilegiado para conocer la sociedad. Por medio de una manifestación artística concreta como la música clásica contemporánea hemos podido ver de qué forma se articulan unos discursos que constantemente oscilan entre el materialismo económico y lo etéreo del arte.

En el caso de los abonados sinfónicos, hemos comprobado como los factores económicos puestos en juego -el precio del abono, la proximidad del auditorio y el gusto por el repertorio ofertado- permiten coser las suturas del grupo. De esta forma, se puede desarrollar un sentido de comunidad cohesionada más allá de la fractura que establece la distinción basada en el diferente nivel de capital cultural institucionalizado. Esta fisura se explicita de una forma muy evidente en el caso de la música clásica contemporánea. La ausencia, habitual en esta música, de una melodía reconocible y la falta de herramientas para descodificar el mensaje dejan a una parte del auditorio en situación de inferioridad. Aquí, incluso, la relación dentro del grupo se estable en términos de lógica docentediscípulo. Los abonados, conscientes del ingente coste que supone la programación sinfónica, se oponen a una mayor programación de música clásica contemporánea. La ecuación, en este caso, vincula la ausencia de público con la insostenibilidad del proyecto.

En el terreno de los intérpretes y los compositores, hemos identificado la incidencia del efecto Arrow generalizado y hemos podido constatar la estrecha relación con el ámbito académico -ya que supone, en muchos casos, la mayor fuente de ingresos-. A través de la formación hemos visto como, según el contexto socioeconómico del músico, el coste de los estudios -instrumentos, materiales, cursos, viajes- se planteaba de forma más explícita o, directamente, se omitía. Esta parte de la biografía personal se podía abordar, también, con alusiones al capital humano y el capital cultural $y$, también, con una valoración de la experiencia formativa que conjuga las parejas mejor-peor, pasado-presente y dentro-fuera.

Respecto a la música clásica contemporánea, hemos observado un punto de inflexión entre las generaciones anteriores a 1959 y las posteriores a 1960. Para los primeros, las nuevas formas de composición son el elemento revolucionario y, para los segundos, lo es la adscripción a otros lenguajes estilísticos -incluidos los más tradicionales-. Esta situación, además, se vincula a la posición de dominio que se puede ejercer desde los conservatorios.

El divorcio entre el público y los creadores actuales se acepta como una realidad social. A pesar de ello, los compositores niegan en sus discursos que realicen una música onanista o con ánimo de desagradar. Así, la responsabilidad de este fracaso cultural se puede repartir, según la posición discursiva, entre el creador, el público y el gestor cultural encargado de la programación. 
Finalmente, en el apartado de los gestores públicos y directivos de conservatorio hemos podido identificar los objetivos principales de su tarea: la preparación de los futuros profesionales y el éxito de taquilla de la oferta programada. Para obtener dicho logro, unos se ubican en una posición más mercantilista -de gestión de recursos- mientras que otros consideran su labor un trabajo creativo. La música clásica contemporánea constituye, aquí, un reto aún más complejo dado el consabido rechazo del público y las dificultades logísticas para poner en escena las nuevas creaciones. Todo esto, les lleva a identificar el agotamiento del modelo actual.

Las formas, pues, de entender este complejo conflicto oscilan entre la responsabilidad por dar una formación completa al alumnado y crear un patrimonio musical de nuestro tiempo y el gusto por compartir un producto artístico que puede despertar placer. Ahora bien, esta disparidad de posiciones, se homogeneiza en el momento de plantear la renovación y aquí aparece la necesidad de cambiar los reclamos, de comunicar de otra manera y, en definitiva, de dejar de centrar el interés en el qué de la programación -el repertorio- para dedicar los esfuerzos a diseñar el cómo, esto es, la forma en la que se va a comunicar la música.

En conclusión, la música y los sujetos que se desarrollan en su campo social no pueden perder de vista el sentido de proceso comercial e industrial inherente. Desde la formación hasta la puesta en música, todas las etapas se relacionan con elementos económicos. La música clásica contemporánea y la crisis que provoca en el campo, obligan a replantear el proceso en su conjunto. Las soluciones, en cualquier caso, vendrán de la mano de la creatividad y serán, también, nuevas formas de arte. 


\section{REFERENCIAS BIBLIOGRÁFICAS}

Adorno, T. W. (2009). Disonancias: Introducción a la sociología de la música. Tres Cantos: Ediciones Akal.

Ariño Villarroya, A. (2007). Música, democratización y omnivoridad. Política y Sociedad, 44, 131-150.

Attali, J. (1977). Ruidos: ensayo sobre la economía política de la música. València: Ibérica de Ediciones y Publicaciones.

Aviñoa, X. (2009). El públic actiu. En La música i el seu reflex en la societat (pp. 39-47). Barcelona: Indigestió Musical SL.

Blacking, J. (2007). Música, cultura e experiência. Cadernos de Campo, 16, 201-218.

Blacking, J. (2010). ¿Hay música en el hombre?. Madrid: Alianza Editorial.

Born, G. y Hesmondhalgh, D. (Eds.). (2000). Western Music and Its Others. London: University of California Press.

Bourdieu, P. (1987). Los tres estados del capital cultural. Sociológica, 5, 11-17.

Bourdieu, P. (1990). Algunas propiedades de los campos. In P. Bourdieu (Ed.), Sociología y Cultura (pp. 135-141). México: Conaculta.

Bourdieu, P. (1991). La distinción: criterio y bases sociales del gusto. Madrid: Taurus.

De La Fuente, E. (2007). The 'New Sociology of Art': Putting Art Back into Social Science Approaches to the Arts. Cultural Sociology, 1(3), 409-425.

Fouce Rodríguez, H. (2010). De la crisis del mercado discográfico a las nuevas prácticas de escucha. Comunicar, 17(34), 65-72.

Hennion, A. (2010). Gustos musicales: de una sociología de la mediación a una pragmática del gusto. Comunicar, 17(34), 25-33.

Hormigos Ruiz, J. (2008). Música y sociedad: análisis sociológico de la cultura musical de la posmodernidad. Madrid: Ediciones y publicaciones Autor.

Idhe, D. (2007). Listening and voice: Phenomenologies of sound. Albany: State University of New York Press.

Iglesias Lozano, I. (2001). Situación actual del sector de la música en España. Información Comercial Española, ICE: Revista de Economía, 792, 139-150.

Martí i Pérez, J. (2000). Más allá del arte: la música como generadora de realidades sociales. Sant Cugat del Vallès: Deriva Editorial. 
Mas i Sempere, X. (2013). La presència de la música clàssica contemporània als auditoris de I'Estat espanyol. En L. Arroyo Moliner y M. Simó Solsona (Eds.), VI Congrés Català/Internacional de Sociologia. Societats i cultures, més enllà de les fronteres: Publicacions completes (pp. 618-641). Associació Catalana de Sociologia - Institut d'Estudis Catalans.

Merriam, A. (2001). Definiciones de "musicología comparada» y "etnomusicología»: una perspectiva histórico-teórica. In F. Cruces \& E. All (Eds.), Las culturas musicales: lecturas en etnomusicología (pp. 59-78). Madrid: Editorial Trotta.

Nettl, B. (2001). Últimas tendencias en etnomusicología. In F. Cruces \& E. All (Eds.), Las culturas musicales: lecturas en etnomusicología (pp. 115-154). Madrid: Editorial Trotta.

Nowak, R. (2016). Consuming Music in the Digital Age: Technologies, Roles and Everyday Life. Basingstoke: Palgrave Macmillian.

Philo, G., \& Miller, D. (2010). Els mercats assassins: estudis culturals, mitjans de comunicació i conformisme. València: Publicacions de la Universitat de València.

Roche Cárcel, J. A. y Oliver Narbona, M. (2005). Cultura y globalización: entre el conflicto y el diálogo. Sant Vicent del Raspeig: Publicacions de la Universitat d'Alacant.

Silbermann, A. (1967). Estructura social de la música. Madrid: Taurus.

Simmel, G. (2003). Estudios psicológicos y etnológicos sobre música. Buenos Aires: Editorial Gorla.

Small, C. (1998). Musicking. Middletown: Wesleyan University Press.

Tagg, P. (1982). Analysing Popular Music: Theory, Method and Practice. Popular Music, 2, 37-67.

Weber, M. (2002). Economía y sociedad: esbozo de sociología comprensiva. Madrid: Fondo de 